\title{
The Structures of the $[\mathrm{M}-\mathrm{H}]$ Anions of the $\mathrm{CH}_{3} \mathrm{NO}_{2}$ Isomers Nitromethane and Methyl Nitrite
}

\author{
Deborah A. Thomas, John E. Bloor, and John E. Bartmess \\ Department of Chemistry, University of Tennessee at Knoxville, Knoxville, Tennessee, USA
}

The 60-u anion observed in the ion/molecule chemistry of methyl nitrite is shown to have the structure $\mathrm{O}=\mathrm{NCH}_{2} \mathrm{O}^{-}$, and not that of the expected deprotonation product ${ }^{-} \mathrm{CH}_{2} \mathrm{ONO}$, by the use of mass-analyzed ion kinetic energy spectrometry, ion/molecule reactivity, and ab initio calculations. (/ Am Suc Mass Spectrom 1990, 1, 295-300)

$\mathrm{M}$ Tethyl nitrite $\mathbf{1}$ is commonly used in chemical ionization mass spectrometry (CIMS) and ion-molecule reaction studies as a source of methoxide, which is generated by thermal electron dissociative attachment $[1,2]$. Further reaction of methoxide with 1 yields an $[\mathrm{M}-\mathrm{H}]$ anion at $60 \mathrm{u}$. This jon has been represented [3] as 2, a dipole-stabilized carbanion [4]. On the basis of the acidities of methanol [5] and other known dipole-stabilized anions [4], however, it seemed likely to us that the reaction of methoxide with 1 to form 2 should be considerably endothermic. If anion 2 is envisioned in the geometry that is most favorable for most dipole-stabilized anions, with the lone pair of the carbanion syn to a transoid nitrosyl group [4], then there is a lone pair on the nitrosyl group proximate to the carbanion. Such a structure should be destabilized with respect to a carbonyl-stabilized carbanion. There are two possibilities that may explain the presence of a $60-\mathrm{u}$ anion. 1 might be rearranging in the vacuum system to the isomeric nitromethane 3. with deprotonation by methoxide now $24 \mathrm{kcal} / \mathrm{mol}$ exothermic [5], or the $[\mathrm{M}-\mathrm{H}]^{-}$ion may not be the straightforward deprotonation product of 1 but rather some rearranged structure.

There are other possible isomers of the formula $\mathrm{CH}_{2} \mathrm{NO}_{2}{ }^{-}$that could reasonably be accessed in such a rearrangement, such as 5 and 6 from neutral formyl hydroxamate 7, or nitrosomethoxide 8 from the (unstable) nitrosomethanol 9 . The barrier for the rearrangement of methyl nitrite to nitromethane has been shown to be $53 \mathrm{kcal} / \mathrm{mol}[6]$ and calculated at a very high level of $\mathrm{Cl}$ to be $67 \mathrm{kcal} / \mathrm{mol}$ [7]. This implies that the rearrangement probably does not occur for the neutral species, but rather occurs during the course of the ion-molecule chemistry. Therefore, the structures of the 60-u anions from 1 and several isomers have been examined by mass-analyzed ion kinetic energy spectrometry (MIKES) experiments, gas-phase

Address reprint requests to John E. Bartmess, Department of Chemistry, University of Tennessee, Knoxville, TN 37996-1600. ion-molecule reactions, and molecular orbital (MO) calculations. The results indicate that 8 is the structure of the 60-u anion produced from 1.

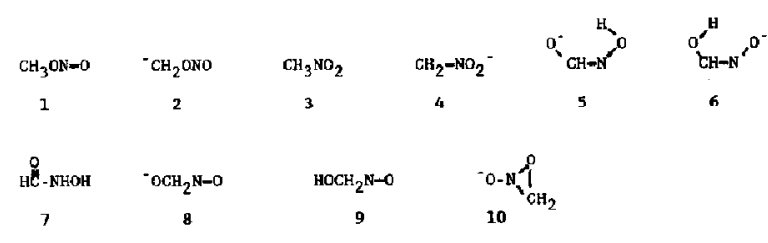

\section{Experimental}

The negative chemical ionization (NCI) mass spectra and MIKES were obtained on a VG ZAB-EQ instrument with reverse geometry controlled by a VG 11250J computer system. Ammonia was used as the CI gas for nitromethane experiments, either methane or nitrogen was used as the $\mathrm{CI}$ gas for methyl nitrite experiments, and methane was used as the $\mathrm{CI}$ gas for formyl hydroxamate experiments. Typical $\mathrm{Cl}$ gas pressure was $1 \times 10^{-4}$ to $5 \times 10^{-4}$ torr. For MTKES with collision-induced dissociation (CID), helium was used at $1-5 \mu$ torr, giving $50-80 \%$ reduction of the parent peak. All gases were reagent grade.

The ion-molecule work was performed on a homebuilt pulsed ion cyclotron resonance (ICR) mass spectrometer run by a dedicated IBM PC [8]. A 1-in. cubic cell and $1 \mathrm{~T}$ field strength were used. Sample pressures of about 1-5 $\mu$ torr were typical. Data were obtained by the rapid scan technique [9]. Nitrogen trifluoride $\left(\mathrm{NF}_{3}\right)$, which produces fluoride upon electron impact, was used to generate the $[\mathrm{M}-\mathrm{H}]$ anion of $\mathrm{MeNO}_{2}$.

Methyl nitrite was synthesized in situ by mixing isoamyl nitrite and methanol [2]. The existence of methyl nitrite in the vapor phase above this mixture was confirmed by Fourier transform infrared (FT IR) analysis of the headspace gas; the spectrum obtained agreed with the published spectrum of methyl nitrite [10]. In addition, on the basis of vapor pressure data [11], one would expect the vapor above an 
<smiles>Fc1c(F)c(F)c(F)c(F)c1F</smiles><smiles>O=[N+]([O-])CC1(F)C(F)=C(F)C(F)=C(F)C1(F)C[N+](=O)[O-]</smiles>

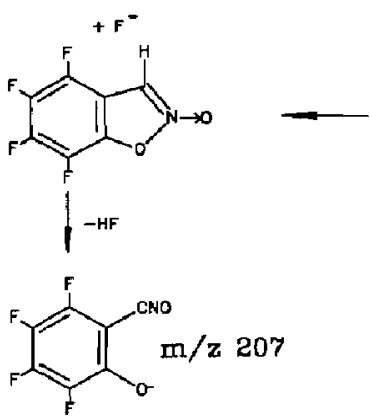<smiles>CCOC=C1C2C(F)=C(F)C(F)=C(F)[C@@]2(F)ON1OCC</smiles>

Scheme I

employing the $6-31+G / / 6-31+G$ basis set [24] have been done on a number of the anions of interest here and their corresponding conjugate acids. Correlation energy will probably make some difference in the relative energies of these structures, owing to the appreciably different bonding types involved. At an uncertainty level of $\sim 5 \mathrm{kcal} / \mathrm{mol}$, however, we believe that the preHartree-Fock level calculations given here are sufficient to guide our interpretation of the energetics. As shown in Tables 5 and 6 , the calculations indicate that deprotonation of methyl nitrite by methoxide to form 2 is 25 $\mathrm{kcal} / \mathrm{mol}$ endothermic. This calculated acidity is close to that observed experimentally for $\mathrm{CH}_{3} \mathrm{OCH}_{3}$ [25] at 407 $\mathrm{kcal} / \mathrm{mol}$. In both $\mathrm{CH}_{3} \mathrm{OCH}_{2}^{-}$and 2 , the carbanion is attached to an oxygen atom, so polar effects should be comparable. There is no possibility of any extra "dipolar stabilization" in $\mathrm{CH}_{3} \mathrm{OCH}_{2}^{-}$, however, so it is unlikely that there is any dipolar stabilization involved in 2. In absolute energies, carbanion 2 is the least stable; then methyl nitronate 4 and nitrosomethoxide 8 are comparable and $51 \mathrm{kcal} / \mathrm{mol}$ more stable than 2 . Finally, 6 is $30 \mathrm{kcal} / \mathrm{mol}$ more stable than 4 and 8 . For the conjugate acids, the calculations place methyl nitrite at
$-1.8 \mathrm{kcal} / \mathrm{mol}$ (more stable) from nitromethane, while experimentally it is less stable by $+2.0 \mathrm{kcal} / \mathrm{mol}$ [26]. The calculated acidity of nitrosomethanol 9 agrees well with the observed bracketed acidity of the 60- $u$ anion from methyl nitrite, though we note that no zero-point energy correction has been applied to convert the calculated $\Delta \mathrm{E}$ to $\Delta H[24]$. The calculations thus support 8 as the structure of the 60-u anion from 1 .

One further line of information arises from linear free energy relationships. The acidity of $\mathrm{HOCH}_{2} \mathrm{~N}=\mathrm{O}$ as an alcohol can be predicted from the $\rho_{1}$ for the gasphase acidities of $\mathrm{RCH}_{2} \mathrm{OH}$ [27]. Using a revised value of $\rho_{\mathrm{I}}$ of $20.3 \mathrm{kcal} / \mathrm{mol}$ [5] and $\sigma_{\mathrm{I}}(\mathrm{NO})=0.37$ [28], a $\Delta H_{\text {acid }}$ of $364.5 \mathrm{kcal} / \mathrm{mol}$ is calculated, quite close to the observed acidity of $368 \pm 4 \mathrm{kcal} / \mathrm{mol}$ for the $60-\mathrm{u}$ anion from 1 and the calculated $\Delta E_{\text {acid }}$ of $364.8 \mathrm{kcal} / \mathrm{mol}$.

On the basis of all these lines of argument, we conclude that the 60-u anion from 1 has structure 8 . There are two reasonable mechanisms for formation of 8. As shown in Scheme II, path A involves initial formation of 2 in an ion-molecule complex followed by unimolecular rearrangement through a cyclic intermediate 10, which breaks the ring $\mathrm{N}-\mathrm{O}$ bond to

Table 5. $\mathrm{Ab}$ initio calculations on $[\mathrm{M}-\mathrm{H}]$ anions from isomers of $\mathrm{CH}_{3} \mathrm{NO}_{2}$

\begin{tabular}{|c|c|c|c|c|c|c|c|}
\hline $\begin{array}{l}\text { Neutral } \\
\text { Species }\end{array}$ & & $\Delta \Delta E_{\mathrm{f}}^{\mathrm{a}}$ & Anion & & $\Delta \Delta E_{\mathrm{f}}^{\mathrm{a}}$ & $\Delta E_{\text {acid }}^{\mathrm{b}}$ & $\Delta H_{\text {acid }}(\operatorname{exptl})$ \\
\hline $\mathrm{CH}_{3} \mathrm{NO}_{2}$ & 3 & $(0.0)$ & $\mathrm{CH}_{3}=\mathrm{NO}_{2}^{-}$ & 4 & 10.01 & 351.8 & $356.4^{c}$ \\
\hline $\mathrm{CH}_{3} \mathrm{ONO}$ & 1 & -1.8 & $-\mathrm{CH}_{2} \mathrm{ONO}$ & 2 & 51.3 & 405.0 & \\
\hline $\mathrm{HOCH}_{2} \mathrm{NO}$ & 9 & -13.1 & $-\mathrm{OCH}_{2} \mathrm{NO}$ & 8 & -0.2 & 364.7 & $(368)^{d}$ \\
\hline OCHNHOH & 7 & -46.8 & $-\mathrm{OCH}=\mathrm{NOH}$ & 5 & -30.5 & 368.1 & \\
\hline
\end{tabular}

a $6-31+G / / 6-31+G$, Gaussian 86. All values are kcal/mol relative to the first compound in the column.

$\Delta E$ (anion) $-\Delta E$ (neutral) +365.7

c Ref 5.

d This work. 
Table 6. Calculated thermochemistry for possible 60-u anion structures

\begin{tabular}{llll}
\hline Reaction & & $\Delta E_{\mathrm{rxn}}^{\mathrm{a}}$ \\
\hline $\mathrm{MeO}$ & & \\
& $\mathrm{MeOH}+{ }^{-} \mathrm{CH}_{2} \mathrm{ON}=\mathrm{O}$ & $(2)$ & +25 \\
$\mathrm{MeOH}+\mathrm{CH}_{2}=\mathrm{NO}_{2}^{-}$ & $(4)$ & -26 \\
$\mathrm{MeOH}+-\mathrm{OCH}_{2} \mathrm{~N}=\mathrm{O}$ & $(8)$ & -26 \\
$\mathrm{MeOH}+-\mathrm{OCH}=\mathrm{NOH}$ & $(5)$ & -57 \\
\hline
\end{tabular}

- $6-31+\mathrm{G} / / 6-31+\mathrm{G}$, Gaussian 86, $\mathrm{kcal} / \mathrm{mol}[24]$.

give the final oxyanion 8 . It might be argued that $\mathbf{1 0}$ could just as easily cleave a $\mathrm{C}-\mathrm{O}$ bond to open to 4, of comparable stability to 8 . To examine this point, we have used semiempirical $\mathrm{MO}$ calculations to explore the reaction pathways postulated here. These were employed because of the prohibitive cost of investigating reaction surfaces of this complexity with ab initio calculations. Most existing semiempirical methods are notorious for not obtaining reasonable energies when dealing with $\mathrm{N}-\mathrm{O}$ bonds: The MNDO method* [29] calculates 1 to be $-40 \mathrm{kcal} / \mathrm{mol}$ (more stable) from 3 (experimental: $+2 \mathrm{kcal} / \mathrm{mol}$ less stable), whereas $A M 1$ [30], an improved version of $M N D O$, results in 1 being $-22 \mathrm{kcal} / \mathrm{mol}$ from 3 . These methods are clearly not appropriate to the present problem. The recent PM3 Hamiltonian [31], however, places 1 at $+6.8 \mathrm{kcal} / \mathrm{mol}$ from 3 , in the right direction and of the right order of magnitude. We have thus used this newer method** to examine various reasonable pathways on the reaction surface. For the isomerization of $-\mathrm{CH}_{2} \mathrm{ONO}\left[\Delta H_{\mathrm{f}}(\mathrm{PM})=-10.7 \mathrm{kcal} / \mathrm{mol}\right]$ to $-\mathrm{OCH}_{2} \mathrm{NO}\left[\Delta \mathrm{H}_{\mathrm{f}}(\mathrm{PM} 3)=-38.7 \mathrm{kcal} / \mathrm{mol}\right]$, a barrier of $7.6 \mathrm{kcal} / \mathrm{mol}$ is found. The geometry of the transition state is roughly that of $\mathbf{1 0}$, but with the nitrogen of the $\mathrm{NO}$ group $2.0 \AA$ from both the $\mathrm{C}$ and the $\mathrm{O}$ in the nominal three-member ring. This is not an exact transition state (based on one negative frequency), because the $\mathrm{C}-\mathrm{O}-\mathrm{N}$ bond angle in 2 was simply reduced until a maximum in energy was found, at $89.5^{\circ}$. Structure 10 at the PM3 level is not an intermediate; no stable point could be found on the reaction surface for such a cyclic structure, using any reasonable bond lengths. No simple transition state for the isomerization of 2

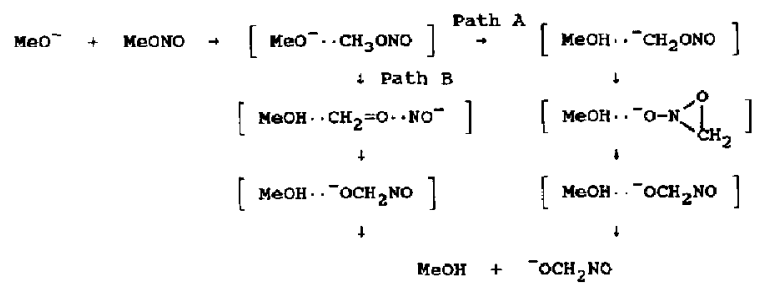

Scheme II

\footnotetext{
* Program No. QCMP004, Quantum Chemistry Program Exchange, In diana University, Bloomington, IN 47405, with extensive modifications by the present authors for more efficient PC operation. See also ref. 29.

** Mopac 5.0, Program No. QCPE 455, Quantum Chemistry Program Exchange, Indiana University, Bloomington, IN 47405.
}

to 4 could be found, either, but, on the basis of an extensive survey of geometries, we believe that any pathway must involve a minimum $\Delta H^{\dagger}>50 \mathrm{kcal} / \mathrm{mol}$. This is consistent with the need to break a $\mathrm{C}-\mathrm{O}$ bond, costing energy, before the $\mathrm{CH}_{2}$ group can rotate, to stabilize the charge by resonance delocalization. For the isoelectronic neutral system, $\mathrm{NH}_{2} \mathrm{ONO}$ rearranging to $\mathrm{NH}_{2} \mathrm{NO}_{2}$, a barrier of $22 \mathrm{kcal} / \mathrm{mol}$ has been calculated at the MCSCF/6-31G*//4-31G level [32].

Another more likely mechanistic possibility is path $B$ in Scheme II, an $E_{2}$-type elimination in the ion-molecule complex, followed by nucleophilic addition of $\mathrm{NO}^{-}$to the carbonyl group. The net reaction to free $\mathrm{NO}^{-}$and formaldehyde is estimated to be exothermic by $-3.8 \mathrm{kcal} / \mathrm{mol}$ [5], but if the $\mathrm{NO}^{-}$bonds to the formaldehyde to give 8 , the reaction enthalpy is $\sim-26 \mathrm{kcal} / \mathrm{mol}$. In such a complex, there is no simple pathway for the intermediates formaldehyde and $\mathrm{NO}^{-}$ to go to $\mathrm{CH}_{2}=\mathrm{NO}_{2}{ }^{-}$. The $E_{2}$ pathway $\mathrm{B}$ seems more likely than the rearrangement pathway $A$ for energetic reasons also. On the basis of ab initio calculations plus a reasonable estimate of the complexation energy of 15 $\mathrm{kcal} / \mathrm{mol}$ for $\mathrm{MeOH}$ plus $-\mathrm{CH}_{2} \mathrm{ONO}$, the inn-molecule complex for the nonrearranged $\mathrm{MeOH} \ldots-\mathrm{CH}_{2} \mathrm{ONO}$ has been determined to be $\sim 10 \mathrm{kcal} / \mathrm{mol}$ endothermic relative to the reactants methoxide and methyl nitrite. This energy barrier would have to be overcome by rearrangement of the carbanion during proton transfer, which seems unlikely. In contrast, the $E_{2}$ pathway should be mechanistically facile and result in a product ion-molecule complex considerably more stable than the reactants. For $\mathrm{MeOH} \ldots-\mathrm{OCH}_{2} \mathrm{NO}$, we estimate that the complex is $\sim 45 \mathrm{kcal} / \mathrm{mol}$ more stable than the reactants, thus providing the driving force for the reaction. All points on path B should be exothermic relative to the reactants.

\section{Conclusions}

Different fragmentation and reactivity pathways indicate that the structures of the $[\mathrm{M}-\mathrm{H}]$ anions from nitromethane and methyl nitrite are not the same. For the $[\mathrm{M}-\mathrm{H}]^{-}$ion from methyl nitrite, the structures outlined in Table 6 have been considered. All but 8 have been ruled out because of calculated energetics and reactivity and fragmentation experiments. No distinctive reaction of the alkoxide structure expected for 8 was found, other than its apparent proton affinity.

These results raise a serious question with regard to the practice of measuring approximate acidities by the bracketing method. Were such a test applied here, the acidity obtained for methyl nitrite would be wrong by at least $25 \mathrm{kcal} / \mathrm{mol}$. It is imperative that the structure of anions produced in this fashion be verified by the various reaction techniques available.

\section{Acknowledgments}

We thank the National Science Foundation Chemical Instrumentation Program and the State of Tennessee Science Alliance Pro- 
gram for help in purchase of the VG ZAB-EQ mass spectrometer. D.A.T. also thanks the National Science Foundation for grant CHE-8411164 and the Science Alliance for support.

\section{References}

1. Jäger, K.; Henglein, A. Z. Naturforsch. 1967, A22, 700; Hunt, D. F.; Stafford, G. C., Jr.; Crow, F. W.; Russell, J. W. Anal. Chem. 1976, 48, 2098.

2. Caldwell, G.; Bartmess, J. E. Org. Mass Spectrom. 1982, 17, 456.

3. Farid, R.; McMahon, T. B. Int. I. Mass Spectrom. Ion Phys. 1978, 27, 163 .

4. Solution: Beak, P.; Reitz, D. B. Chem. Rev. 1978, 78, 275. Gas phase: Noest, A. J.; Nibbering, N. M. M. J. Am. Chem. Soc. 1980, 102, 6427; Bartmess, J. E.; Caldwell, G.; Rozeboom, M. D. J. Am. Chem. Soc. 1983, 105, 340; Ingemann, S.; Nibbering. N. M. M. J. Org. Chem. 1985, 50, 682 .

5. Lias, S. G.; Bartmess, J. E.; Liebman, J. F.; Holmes, J. L.; Levin, R. D.; Mallard, W. G. Gas-phase ion and neutral thermochemistry, J. Phys. Chem. Ref. Data 1988, 17, Suppl. 1.

6. Wodtke, A. M.; Hintsa, E. J.; Lee, Y. T. I. Phys. Chem. 1986, 90, 3549; Wodtke, A. M.; Hintsa, E. J.; Lee, Y. T. J. Chem. Phys. 1986, 84, 1044.

7. McKee, M. L. J. Phys. Chem. 1989, 93, 7365.

8. McIver, R. T., Jr. Rev. Sci. Instrum. 1970, 41, 555; McIver, R. T., Jr. Rev. Sci. Instrum. 1978, 49, 111; McIver, R. T., Jr. Hunter, R. L.; Ledford, E. B., Jr.; Locke, M. J.; Francl, T. J. Int. J. Mass Spectrom. Ion Phys. 1981, 39, 65; Bartmess, J. E. Caldwell, G. Int. J. Mass Spectrom. Ion Phys. 1981, 41, 125.

9. Hunter, R. L.; Mclver, R. T., Jr. Chem. Phys. Lett. 1977, 49 577; Hunter, R. L.; McIver, R. T., Jr. Am. Lab. 1977, 9, 13; Hunter, R. L.; McIver, R. T., Jr. In Lecture Notes in Chemistry, Vol. 31; Hartmann, H.; Wanczek, K.-P., Eds.; SpringerVerlag: Berlin, 1982.

10. Klaboe, P.; Jones, D.; Lippincott, E. R. Spectrochim. Acta $1967,23 A, 2957$.

11. Handhook of Chemistry and Physics, 58th ed,, CRC: West Palm Beach, FL, 1977.

12. Fishbein, W. N.; Daly, J.; Streeter, C. L. Anal. Biachem. 1969, 28,13 .
13. Su, T.; Chesnavich, W. J. J. Chem. Phys. 1982, 76, 5183.

14. Bursey, M. M.; Harvan, D. J.; Parker, C. E.; Hass, J. R. J. Am. Chem. Suc. 1983, 105, 6801.

15. Stewart, J. H.; Shapiro, R. H.; DePuy, C. H.; Bierbaum, V. M. J. Am. Chem. Soc. 1977, 99, 7650; DePuy, C. H.; Bierbaum, V. M.; King. G. K.; Shapiro, R. H. J. Am. Chem. Snc. 1978, 100, 2921; Hunt, D. F.; Sethi, S. K. I. Am. Chem. Soc. 1980, 102, 6953; Lloyd, J. R.; Agosta, W. C.; Field, F. H. J. Org. Chem. 1980, 45, 3483.

16. Benson, S. W.; Cruickshank, F. R.; Golden, D. M.; Haugen, G. R.; O'Neal, H. E.; Rodgers, A. S.; Shaw, R.; Walsh, R. Chem. Rev. 1969, 69, 279.

17. Farneth, W. E; Brauman, J. I. J. Amt. Chem. Soc. 1976, 98, 7891.

18. Caldwell, G.; Rozeboom, M. D.; Kiplinger, J. P.; Bartmess, J. E. I. Am. Chem. Soc. 1984, 106, 4660.

19. Lehman, T.; Bursey, M. M. Ion Cyclotron Resonance Spectrometry; Wiley: New York, 1976.

20. Bierbaum, V. M.; DePuy, C. H.; Shapiro, R. H. J. Am. Chem. Soc. $1977,99,5800$.

21. DePuy, C. H. Org. Mass Spectrom. 1985, 20, 556.

22. Grabowski, J. J.; Zhang, L. J. Am. Chem. Soc, 1989, 111, 1193.

23. Ingemann, S.; Nibbering, N. M. M.; Sullivan, S. A.; DePuy, C. H. J. Am. Chem. Soc. 1982, 104, 6520.

24. Chandrasekar, J.; Andrade, J. G.; Schleyer, P. v. R. J. Am. Chem. Soc. 1981, 103, 5609, 5612

25. Deluy, C. H.; Bierbaum, V. M.; Damrauer, R. J. Am. Chem. Soc. 1984, 106, 4051.

26. Pedley, J. B.; Rylance, J. Sussex-NPL computer analysed thermochemical data: organic and organometallic compounds, Univ. Sussex, Brighton 1977.

27. Bartmess, J. E.; Scott, J. A.; Mclver, R. T., Jr. I. Am. Chem. Soc. 1979, 101, 6056

28. Hine, J. Structural Effects on Equilibria in Organic Chemistry; Wiley: New York, 1975.

29. Dewar, M. J. S.; Thiel, W. I. Am. Chem. Soc. 1977, 99, 4899; Dewar, M. J. S.; Rzepa, H. S. J. Am. Chem. Soc. 1978 , 100, 784.

30. Dewar, M. J. S.; Zoebisch, E. G.; Healy, E. F.; Stewart, J. P. J. I. Am. Chem. Soc. 1985, 107, 3902; Dewar, M. J. S.; Dieter, K. M. J. Am. Chem. Soc. 1986, 108, 8075.

31. Stewart, J. J. P. J. Comp. Chem. 1989, 10, 221.

32. Saxon, R. P.; Yoshimine, M. J. Phys. Chem. 1989, 93, 3130. 